\title{
Dropping Simulation of Printed Circuit Board with BGA Soldering Assembly for Optical Module Application
}

\author{
Shouxu Wang ${ }^{1}$, Yunzhao Chen ${ }^{1}$, Li Zheng ${ }^{1}$, Yuanming Chen ${ }^{1}$, Huaiwu Zhang ${ }^{1}$, Lijun Gong ${ }^{2}$, Bei Chen ${ }^{2}$ \\ and Wei $\mathrm{He}^{1,3^{*}}$ \\ ${ }^{1}$ State key laboratory of electronic thin films and integrated devices, University of Electronic Science and Technology of China, \\ Chengdu 610054, P. R. China. \\ ${ }^{2}$ Guangzhou Fastprint Circuit Tech Co., Ltd, Guangzhou, 510663, China. \\ ${ }^{3}$ Research and development department, Guangdong GuanghuaSci-Tech Co., Ltd., Shantou 515000, China. \\ ${ }^{*}$ Corresponding author
}

\begin{abstract}
In this paper, finite element analysis was carried out to simulate the response of printed circuit board (PCB) assembly that fell and collided with a rigid surface using dropping simulation. The drop process was simulated by setting the drop parameters including falling directions and falling heights. The results revealed that $180^{\circ}$ drop had the most severe damage for BGA solder joints. It also indicated that dynamic bending of the PCB resulted from the solder stress.
\end{abstract} drop

Keywords-printed circuit board; ball grid array; simulation;

\section{INTRODUCTION}

Printed circuit board (PCB) exhibits high density interconnection to realize high-speed signal transmission ${ }^{[1]}$. The reliability of PCB with gall grid array (BGA) soldering has become increasingly prominent since the popularity of all kinds of portable electronic products. One of the most important reliability problems is impact resistance according to the research $^{[2,3]}$. Once device inevitably dropped, it might damage internal electronic component which is mainly caused by electronic packaging BGA solder joint failure. Thus, the reliability performance of solder joints is required for the formation of full reliability. This paper used the finite element to perform the board-level drop simulation of BGA solder joints. This method can evaluate the stress of BGA solder joints easily and quickly on different location of PCB with BGA soldering assembly to provide guidance to obtain a highly reliable electronic product with dropping and impact resistance for optical module application.

\section{SIMULATION EXPERIMENT}

\section{A. Simulation Experiment}

In the finite element simulation model, PCB assembly was designed as three-layer structure including BGA substrate, solder ball array and PCB. The solder balls ( $\mathrm{SnAg0.5Cu \text {) }}$ were arranged in a regular matrix $(6 \times 6)$, the center distance of adjacent solder balls was $4.5 \mathrm{~mm}$. In this paper, the method of homogenized material parameters was adopted to simplify PCB model ${ }^{4]}$. The materials in this paper were regarded as linear elastic model ${ }^{[5]}$ and it was shown in Table I.
TABLE I. MATERIAL PARAMETERS OF PCB MODEL

\begin{tabular}{|c|c|c|c|}
\hline Material & PCB & Chip & Solder ball \\
\hline Density(g/cm $\left.{ }^{3}\right)$ & 1.15 & 2.33 & 7.5 \\
\hline $\begin{array}{c}\text { Elastic } \\
\text { Modulus(Gpa) }\end{array}$ & 25 & 131 & 43 \\
\hline Poisson's ratio & 0.39 & 0.3 & 0.34 \\
\hline $\begin{array}{c}\text { Geometric } \\
\text { dimensions(mm) }\end{array}$ & $185 \times 102 \times 1.5$ & $25 \times 25$ & $\begin{array}{c}\text { Diameter:0.7, } \\
\text { Height:0.48 }\end{array}$ \\
\hline
\end{tabular}

\section{B. Drop Parameter}

Drop parameters include gravity acceleration, drop height, drop angle, and initial velocity. 7 sets of control experiments were designed to achieve the simulation shown in Table II. The ground property was rigid, the contact damping and the initial velocity were 0 . There were four drop angles as shown in Figure I. Solder joints were divided into fine-grid, the PCB was divided into coarse grid, as shown in the Figure II.

TABLE II. DROPPING PARAMETERS

\begin{tabular}{|c|c|c|}
\hline Group & Drop angle & Drop height (m) \\
\hline 1 & $180^{\circ}$ & 1 \\
\hline 2 & $45^{\circ}$ & 1 \\
\hline 3 & $90^{\circ}$ & 1 \\
\hline 4 & $0^{\circ}$ & 1 \\
\hline 5 & $180^{\circ}$ & 2 \\
\hline 6 & $180^{\circ}$ & 5 \\
\hline 7 & $180^{\circ}$ & 10 \\
\hline
\end{tabular}

(a) drop angle is $0^{\circ}$;

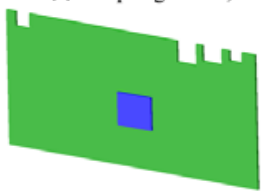

(b) drop angle is $180^{\circ}$

(c) drop angle is $90^{\circ}$

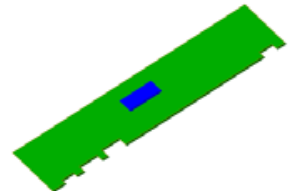

(d) drop angle is $45^{\circ}$

FIGURE I. DIFFERENT DROP ANGLE OF PCB 


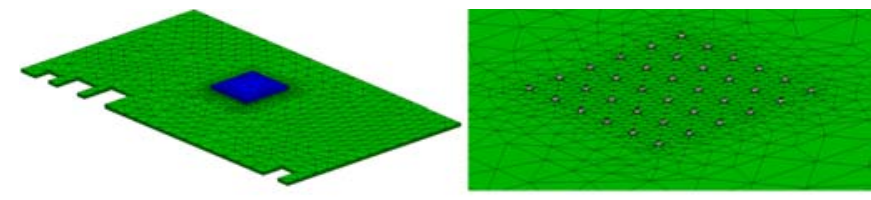

FIGURE II. FINITE ELEMENT MESH OF PCB

\section{RESUltS AND DisCUSSION}

\section{A. Stress Analysis of Solder Joint Array}

The result of stress distribution of the solder joint array was shown in Figure III. The maximum value of the solder joint stress in each row appeared the left and right end joints. The maximum stress value of the first row, third row, sixth row were extracted from the results, as shown in Figure IV. It displayed the maximum value of stress was located on the top and bottom two corners of the first and six column joints, and the maximum stress was almost the same as the two point. Influences of drop angle of PCB

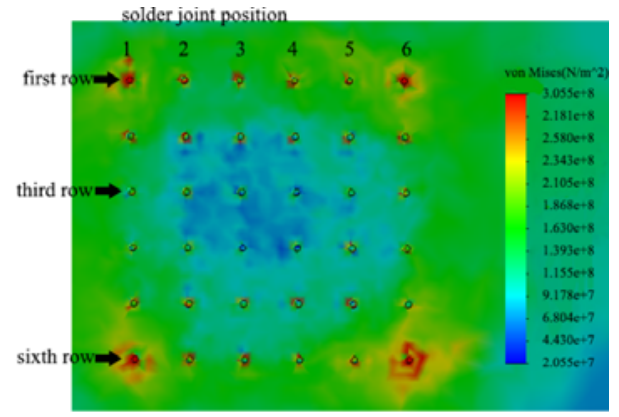

FIGURE III. STRESS DISTRIBUTION OF SOLDER JOINT ARRAY

Four kinds of typically drop angle were designed in this experiment. The distribution of stress was shown in Figure $\mathrm{V}$ and BGA solder joints in the first row of four groups were analyzed by drawing the maximum stress of solder joint in
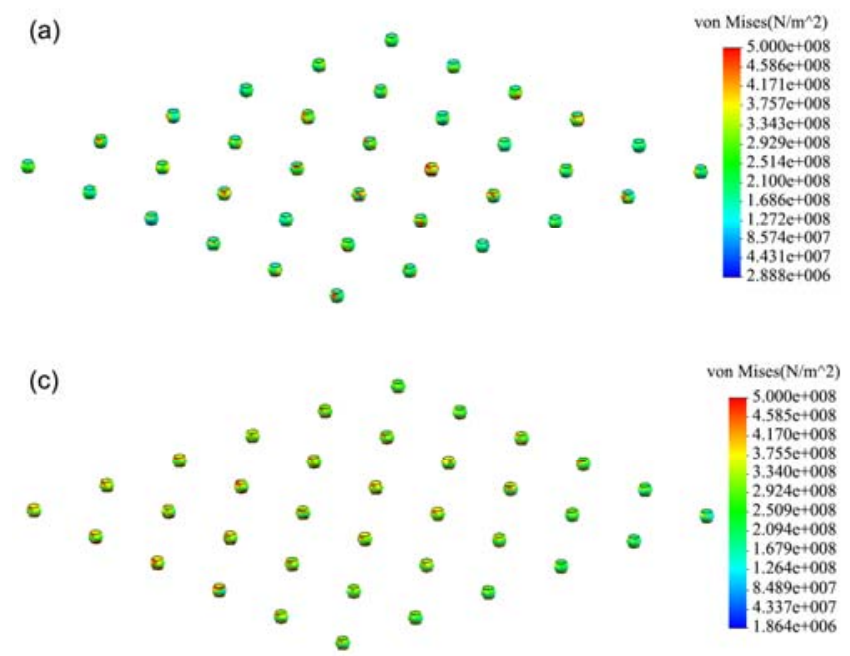

Figure VI. It displayed that the maximum solder joint stress appeared at $180^{\circ}$ drop direction and distributed in four corners of the solder joint array. Therefore the $180^{\circ}$ drop had the most severe damage to the BGA solder joints.

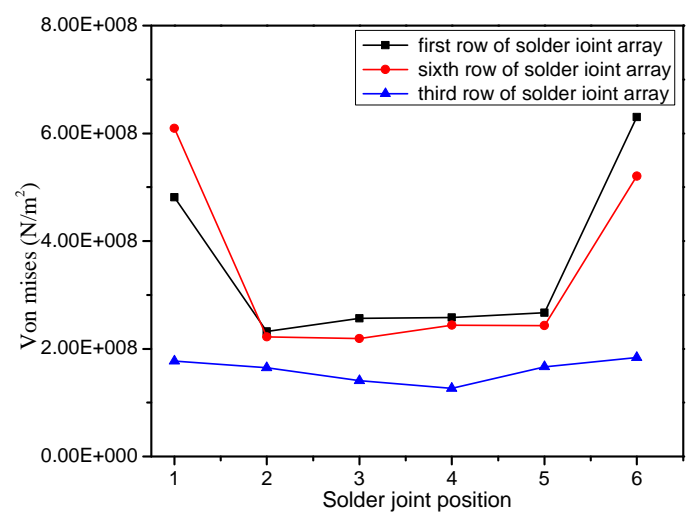

FIGURE IV. MAXIMUM VALUE OF STRESS OF SOLDER JOINT

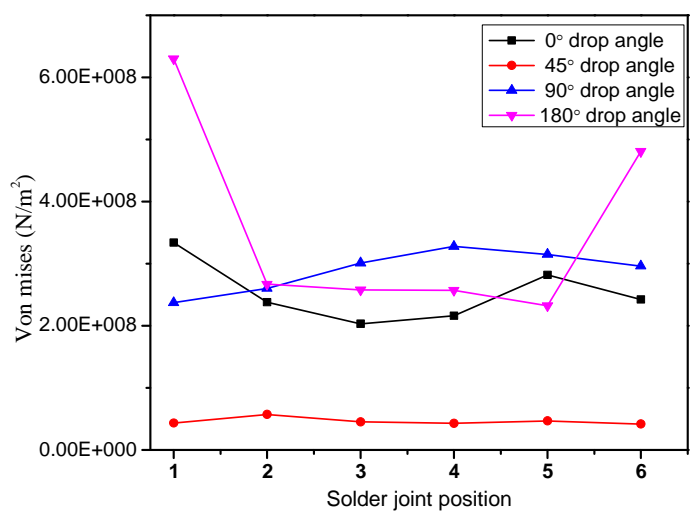

FIGURE V. STRESS OF SOLDER JOINT IN THE FIRST ROW OF ARRAY AT DIFFERENT DROP Angle
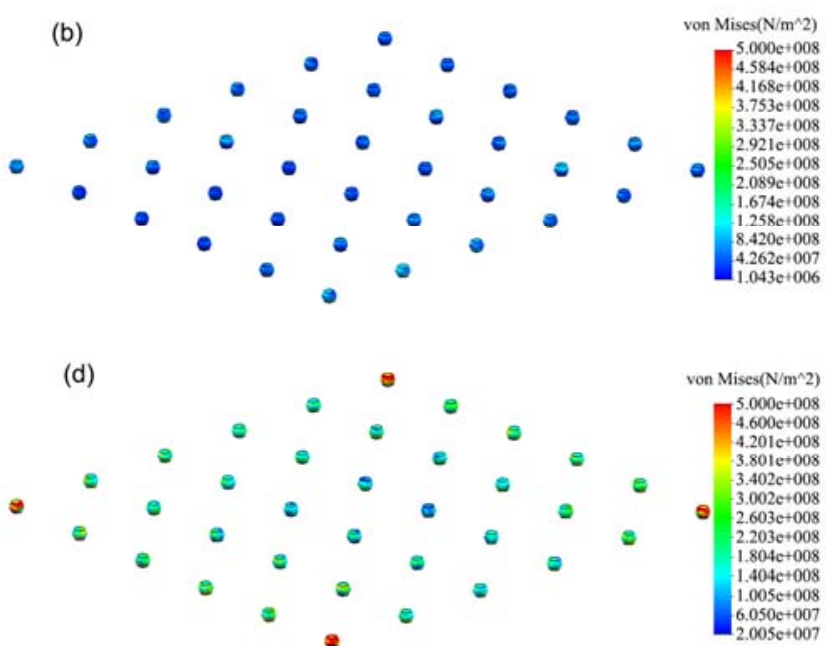


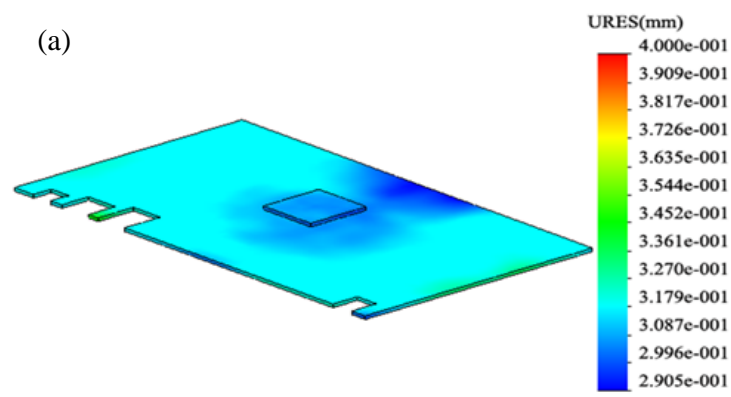

(c)

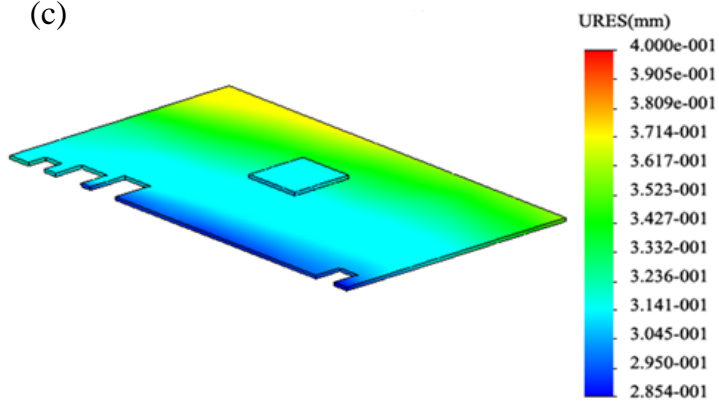

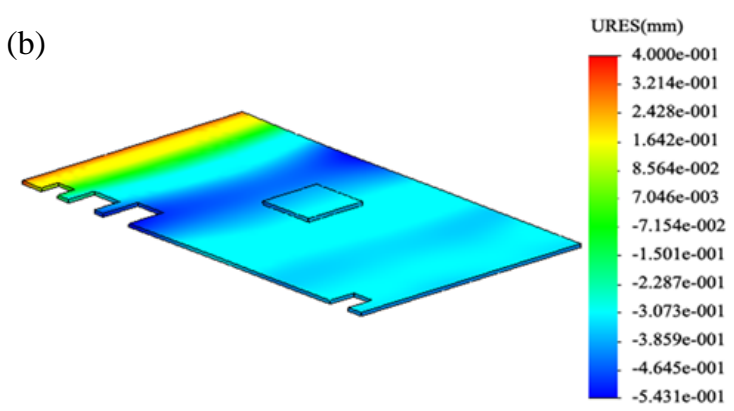

(d)

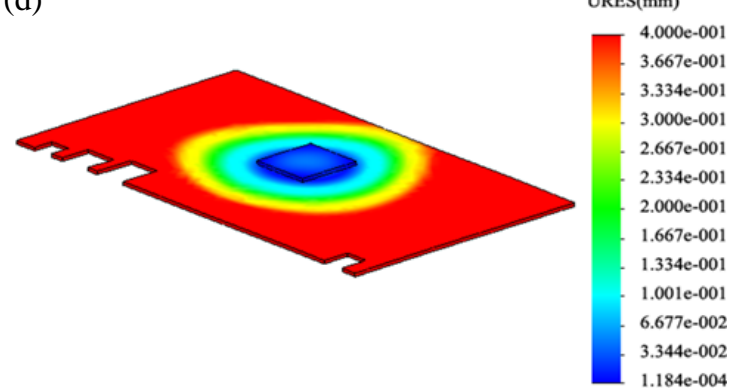

FIGURE VII. DEFORMATION OF PCB AT DIFFERENT DROP ANGLE: (a) $0^{\circ}$; (b) $45^{\circ}$; (c) $90^{\circ}$; (d) $180^{\circ}$

To study the causes of different stress of BGA solder joints while it dropped in different angle, four nephograms of deformation of PCB at different drop angle were calculated and was shown in Figure VII. It described that the $180^{\circ}$ drop has the maximum deformation and it trended to decrease from edge to center. The maximum deformation of PCB and maximum stress of BGA solder joints from group1 to group 7 were analyzed as shown in Figure VIII. It showed strong correlations between the maximum stress and the maximum deformation. Therefore, the deformation of PCB had linear correlations with the stress of BGA solder joints and caused by the bending deformation in drop impact test.

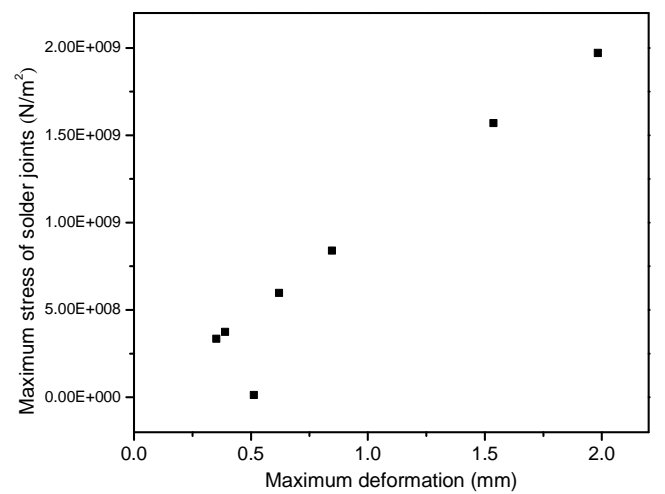

FIGURE VIII. RELATION BETWEEN THE MAXIMUM DEFORMATION OF PCB AND MAXIMUM STRESS OF BGA SOLDER JOINTS

\section{CONCLUSIONS}

A novel and computationally efficient board-level model was developed to investigate board level drop reliability of
PCB assembly for optical module application. Initially, simulations of the board-level drop test were carried out using the homogenized material properties. When critical locations of the solder array were determined, it was found that peak stress occurred at the corner of solder array. It was also confirmed that $180^{\circ}$ drop had the most severe damage to the BGA solder joints. Linear correlation was observed between the maximum deformation of PCB and maximum stress of BGA solder joints. The proposition that bending was the main driver of solder stress was validated by simulations.

\section{ACKNOWLEDGMENT}

The authors gratefully acknowledge the support of Project of Science and Technology Planning of Guangzhou City China (No.201604010086).

\section{REFERENCES}

[1] Y. Chen, W. He, X. Chen, et al,"Plating uniformity of bottom-up copper pillars and patterns for IC substrates with additive-assisted electrodeposition”, Electrochimica Acta, 120, 2014: 293-301.

[2] S. Canumalla, H. D. Yang, P. Viswanadham, et al, "Package to Board Interconnection Shear Strength (PBISS): Effect of Surface Finish, PWB Build-up Layer and Chip Scale Package Structure”, IEEE Transactions on Components and Packaging Technologies, 27 (1), 2004: 182-190.

[3] J. Wang and S. Quander, "The effect of different build-up structure on solder joint fatigue life under thermo mechanical cyclic loading condition”, 2004 EPTC, pp. 330-334

[4] F. Sarvar and P. P. Conway.,"Effective modeling of the reflow soldering process: Basis, construction, and operation of a process model”, IEEE Transactions on Components, Packaging, and Manufacturing Technology, 21(2), 1998:126-133.

[5] J. Luan, T. Y. Tee, X. Zhang, et al,“Solder joint failure modes, mechanisms, and life prediction models of IC packages under board level drop impact”,6th International Conference on Electronic Packaging Technology,2005:382-388. 